\title{
On-Ice Assault: Difficulties in Discerning Consent in Canadian Ice Hockey
}

\author{
Curtis Fogel ${ }^{1}$ \\ ${ }^{1}$ Interdisciplinary Studies, Lakehead University, Orillia, Canada \\ Correspondence: Curtis Fogel, Interdisciplinary Studies, Lakehead University, Orillia, ON., Canada L3V 0B9. \\ Tel: 1-705-330-4008 ext. 2646. E-mail: cafogel@lakeheadu.ca
}

Received: December 10, 2012 Accepted: December 24, 2012 Online Published: July 5, 2013

doi:10.5539/ilr.v2n1p96

URL: http://dx.doi.org/10.5539/ilr.v2n1p96

\begin{abstract}
This paper considers the legal difficulties in prosecuting cases of on-ice violence in Canadian ice hockey, with particular attention to the consent defence. In this paper, a clear definition of consent is established to include: a voluntary agreement to participate in an activity that is free of coercion, deception, or fraud, and is arrived at in a clear mental state by all individuals involved. Using numerous legal case files and secondary literature, various issues of discerning consent in violent sport are discussed including: an unclear criminal code, the voluntary assumption of risk, the problem of line-drawing, honest but mistaken belief, the occurrence of non-specific contact, determining the intent of the accused, and determining liability. Various legal strategies to deal with the issues of discerning consent in violent sport are also discussed.
\end{abstract}

Keywords: consent, violence, ice hockey, sport, law, Canadian Criminal Justice System

"Hockey is a fast, vigorous, competitive game involving much body contact. Were the kind of body contact that routinely occurs in a hockey game to occur outside the playing area or on the street, it would, in most cases, constitute an assault to which the sanctions of the criminal law would apply. Patently when one engages in a hockey game, one accepts that some assaults which would otherwise be criminal will occur and consents to such assaults. It is equally patent, however, that to engage in a game of hockey is not to enter a forum to which the criminal law does not extend. To hold otherwise would be to create the hockey arena a sanctuary for unbridled violence to which the law of Parliament and the Queen's justice could not apply."

$$
\text { R. v. Watson [1975] }
$$

\section{Introduction}

The role of the Criminal Justice System in policing Canadian ice hockey has never been clear. For the most part, the police and courts have let hockey exist in what could be termed a "state of exception", whereby the laws of a particular land are suspended under certain conditions (Agamben 2005:1). Despite the commonality of extreme violence in Canadian hockey leading to concussions, fractures, and even death, few cases have appeared in Canadian courts. Of those, even fewer have resulted in successful convictions by the prosecution. A primary reason for this lack of successful convictions of assault in Canadian ice hockey in the legal notion of volenti non fit injuria, or "to a willing person, injury is not done" (Corbett et al. 2008:28). That is, there is a basic understanding that if an act of violence in sport is consented to, that no crime has occurred. Without such an understanding, violent contact sports like Canadian ice hockey would cease to exist. The aim of this paper is to explore this issue of consent in relation to violence in Canadian ice hockey in terms of: i) how consent is defined in the Canadian legal system, and ii) what difficulties legal officials face in discerning what is and is not consensual violence in sport.

\section{Method}

The methodological approach of this paper is informed by unobtrusive or what is sometimes termed non-reactive measures (Webb et al., 1981). This process entails the use of data that a) involve no human contact, and b) were not created for the direct purpose of academic study. The data used in this study consist of 12 legal case files pertaining to the prosecution of instances of violence in Canadian sport. The legal challenges of prosecuting each crime were examined, revealing several recurrent themes, which are explored in detail in this paper. 


\section{Defining Consent in Canadian Courts of Law}

While the Canadian Criminal Code makes no direct mention of consent relating to violence on the playing field of sport or in ice hockey in particular, the term is widely used in describing various other infractions. For the purposes of this paper, two sections of the Canadian Criminal Code will be examined to develop a clear understanding of what the term consent means in Canadian criminal law. These include: 1) Sections 150-154 pertaining to sexual assault, and 2) Sections 265-268 pertaining to various forms of physical assault. Although this paper aims to explore physical assault in sporting contexts, which typically involves invoking sections 265-268, e.g. R. v. McSorley (2000) where Marty McSorley was charged with aggravated assault with a deadly weapon, the sections on sexual assault have also been included because the legal concept of consent appears to have been described in the most detail here.

Section 151.1(2/3) of the Canadian Criminal Code defines consent as "the voluntary agreement of the complainant to engage in the [activity] in question." Furthermore, this section lists five scenarios where voluntary consent has not been gained including:

a) the agreement is expressed by the words or conduct of a person other than the complainant

b) the complainant is incapable of consenting to the activity

c) the accused counsels or incites the complainant to engage in the activity by abusing a position of trust, power or authority

d) the complainant expresses, by words or conduct, a lack of agreement to engage in the activity; or

e) the complainant, having consented to engage in the [activity], expresses, by words or conduct, a lack of agreement to continue to engage in the activity.

From this, it can be deduced that voluntary consent by Canadian law requires that the consent comes from the individual involved, in a capable mental state, without coercion, with the right of refusal, and that by consenting to an initial activity does not necessarily imply that one consents to all subsequent activities. Section 153.1(5) adds to this by suggesting that the accused must perceive that the act was not consensual. However, if the accused developed this perception in a reckless state of mind or did not take reasonable steps to ascertain the complainant's consent then this perceived consent is void. It must be noted that this discussion of consent in the Canadian Criminal Code pertains to sexual assault, so while it is useful to gain further understanding of what consent means in Canadian law, different factors might be involved in cases of violence in sport.

Criminal cases involving violence in Canadian sport tend to be tried under the physical assault laws in the Canadian Criminal Code (White 1986). While less detail on what voluntary consent entails is contained in this section, the notion of consent is repeated several times. Section 265(1) defines common assault as an application of force to another person without their consent. The conditions under which no consent is given regardless of submission, listed in Section 265(3), include:

a) the application of force to the complainant or to a person other than the complainant

b) threats or fear of the application of force to the complainant or to a person other than the complainant

c) fraud; or

d) the exercise of authority

Like the sexual assault provisions, there is also a common assault provision in Section 265(4) that holds that for a crime to have occurred the accused must have perceived the activity to be non-consensual. If the accused believed that the complainant consented this would constitute a defence. This is commonly referred to as "the consent defence" (Binder 1975:235).

A further provision in the Canadian Criminal Code suggests that the defence of consent is not universal, since not all activities are legalized just because they are consented to. This is clear in Section 14 on 'Consent to Death', which states that: "No person is entitled to consent to have death inflicted on him, and such consent does not affect the criminal responsibility of any person by whom death may be inflicted on the person by whom consent is given." While again, this appears to have little to do with violence in sport, it does reveal that the consent defence is not universal. For example, if players consent to their own use of cocaine of anabolic steroids it does not make these activities any less illegal.

Overall, from these provisions of the Canadian Criminal Code, consent can be defined in Canadian law as: a voluntary agreement to participate in an activity that is free of coercion, deception, or fraud, and is arrived at in a clear mental state by all individuals involved. Additionally, consent is only a limited guarantee of defence 
because the Canadian law does not allow individuals to consent to activities that are believed to cause undue harm, i.e. assisted suicide.

\section{Difficulties of Discerning Consent in Canadian Ice Hockey}

In order to determine criminal liability, the courts must decide on the limits of violence that hockey players consent to in their participation in the sport. This determination is, however, riddled with several issues that make discerning consent in specific instances of on-ice violence difficult. The legal issues of discerning consent in violent Canadian sport that will be discussed include: i) an unclear criminal code, ii) voluntary assumption of risk, iii) the problem of line-drawing, iv) honest-but-mistaken belief, v) the occurrence of non-specific contact, vi) determining the intent of the accused, and vii) determining liability.

There are no provisions that mention consent in the context of sport in the Canadian Criminal Code. The task of lawyers and judges in cases involving violence in sport then becomes to interpret the criminal code, as well any other legal precedents that have been legally entrenched through the interpretations of others. Each case, however, has a unique set of circumstances. For example, in R. v. McSorley (2000), professional hockey player Marty McSorley violently struck his stick against the head of an opposing player named Donald Brashear, who he had engaged in consensual fighting with earlier in the game, and was charged with assault with a deadly weapon. Four years later, another professional hockey player named Todd Bertuzzi appeared in Canadian courts for an incidence of violence in professional ice hockey (R. v. Bertuzzi 2004). In this incident, Todd Bertuzzi struck another player, Steve Moore, in the back of the head with his gloved fist, resulting in two broken vertebra and brain injuries that subsequently ended his hockey career. Bertuzzi was given a conditional discharge on the grounds that he serves 80 hours of community service.

In R. v. Maki (1970) and R. v. Green (1971), two professional hockey players named Wayne Maki and Ted Green appeared in Canadian courts for an altercation involving swinging sticks at one another resulting in horrific injuries to the point of near death. No convictions resulted for either of the men in this incident. While precedents were set in these simultaneous cases, it is difficult to equate them with the McSorley incident, which involved the use of a stick against a player who had openly challenged him to fight, because of other factors like Brashear not fighting back with his stick, and being struck from behind. Likewise, the factors involved in R. v. Brashear (2004) are clearly different as no sticks were involved in the incident.

A second major difficulty in the litigation of cases involving the determination of consent is that sport can be perceived as a voluntary activity; that is, that players knowingly understand the risks of the game and thus, by stepping on they field they are consenting to these risks. The Canadian Criminal Code suggests that consent must be voluntary and free of coercion, deception or fraud. This lends itself to the consent defence, since it appears that players consent to the risks of their sport through voluntary. This is tied to the legal notion of volenti non fit injuria or "to a willing person, injury is not done" (Corbett et al. 2008:28).

Looking at the rulings of the judges in R. v. Green (1971) and R. v. Maki (1970) the value that the Canadian courts place on the voluntary assumption of risk in sport is clear. In R. v. Green (1971) the judge stated:

I think within our experience we can come to the conclusion that this is an extremely ordinary happening in a hockey game and the players really think nothing of it. If you go behind the net of a defenseman, particularly one who is trying to defend his zone, and you are struck in the face by that player's glove, a penalty might be called against him, but you do not really think anything of it; it is one of the types of risk one assumes.

Similarly, the judge in R. v. Maki (1970) stated: "All players, when they step out onto a playing field or ice surface, assume certain risks or hazards of the sport." In both cases, the judges have identified that the players involved voluntarily assumed the risks of their sports and as such, neither player was criminally sanctioned.

Similar sentiments are expressed in Agar vs. Canning(1966), a civil case involving on-ice violence where Canning hit Agar in the face with his stick causing him to lose his eye. The judge stated:

Since it is common knowledge that such injuries are not infrequent, this supports the conclusion that in the past those engaged in this sport have accepted the risk of injury as a condition of participating. Hockey necessarily involves violent bodily contact and blows from the puck and hockey sticks. A person who engages in this sport must be assumed to accept the risk of accidental harm and to waive any claim he would have apart from the game for trespass to his person in return for enjoying a corresponding immunity with respect to other players.

Again, the early decisions of the courts were that stepping onto the ice involves an assumption of risk to being injured by acts of violence in the game. Given this, it appears that by voluntarily participating in sport one is susceptible to violent injury without recourse in the Canadian courts. 
One could, however, debate the actual voluntariness of sport participation (Michigan Law Review Association 1976). A professional athlete cannot just leave the field of play because they feel like the game has become too violent. Doing so would illicit a fine or suspension from their team, possibly a fine from their league, the jeering of fans, and the potential loss of their livelihood. Likewise, in university sports, if a player were to refuse to play or leave the field they would be placing themselves at risk of losing their scholarships, which might be their inroad to getting a university education.

Building on the issue of voluntary participation is the issue of drawing the line of consent. That is, what is the acceptable range or rule-violating behaviours that players voluntarily consent to in sport? Some legal scholars, such as Alexandru-Virgil Voicu (2005), suggest that any behaviour that extends beyond the rules of the game should be open to criminal or civil liability. However, the rules of a given sport are never clear (Michigan Law Review Association 1976). There are, of course, the formal rules that are often laid out in a clear fashion in the rulebook of a given sport; there are also informal rules that govern any given sport. For example, in basketball the rules state that a foul has been committed when a player on defence strikes a player on offence while the offensive player is in the act of shooting. This is the formal rule. The informal rule is that if you are going to foul a player in the act of shooting, you should foul him or her hard enough that they are unable to get the shot up, thus avoiding a potential three-point play.

This suggests that the breaking of formal rules in sport is routine; it is, in fact, part of the game. Given this, a player can still be said to have consented to violent and often injurious actions even if they fall outside of the rules of the game. For example, in R. v. Green (1971) the judge stated that being punched in the face, while outside the formal rules of the game, was an "ordinary happening in a hockey game and the players really think nothing of it." Likewise, in R. v. Cey (1989), the judge stated:

It is clear that in agreeing to play the game a hockey player consents to some forms of intentional bodily contact and to the risk of injury therefrom. Those forms sanctioned by the rules are the clearest example. Other forms, denounced by the rules but falling within the accepted standards by which the game is played, may also come within the scope of the consent.

The rules, then, cannot be used to determine what will be deemed consensual and what is not. The question then remains of where to draw the line; yet, there is no clear formula for how this line can be determined. The judge presiding over R. v. Cey (1989) echoes this difficulty stating, “...the game of hockey involves a continuous series of assaults. Obviously, most of the body contact is consented to merely by the decision to participate in the sport. To determine at what point this consent disappears is not an easy task."

An added complication in cases of on-ice assault involves the notion of honest-but-mistaken belief, which provides the accused with a defence that he or she believed the act was consensual. This is codified in subsection 265(4) of the Canadian Criminal Code as follows:

Where and accused alleges that he believed that the complainant consented to the conduct that is the subject matter of the charge, a judge, if satisfied that there is sufficient evidence and that, if believed by the jury, the evidence would constitute a defence, shall instruct the jury, when reviewing all the evidence relating to the determination of the honesty of the accused belief, to consider the presence or absence of reasonable grounds for that belief.

Given this provision, it is not sufficient for prosecutors to argue that there was no actual consent to the violent act. Instead, it must be determined that the accused did not believe that his violent act was consensual within the sport.

Another difficulty in prosecuting on-ice assault is in determining the intent of the accused. Proving deliberate intent to cause injury was cited by the judge in R v. Henderson (1976) as a means to negate consent. He states:

... an incision across his face which would require 75 stitches... one of the players continues to pummel the other, who at that time is either unconscious or rendered helpless... the use of an instrument such as a hockey stick ... one of the players uses the ice in such a way that the opposing player's head comes into frequent and violent contact with it... Surely these are not the risks which the injured player assumed by participation in the sport... where there is conduct which shows a deliberate purpose to inflict injury, then no immunity is accorded to the offending player.

Based on this, it could be argued that intent to injure could negate consent.

Proving intent is, however, difficult in the context of sport. While in a case like R. v. McSorley (2000) the intent seems clear in that he skated across the ice with his stick up in the air before connecting it with the head of Donald Brashear, not all acts are this obvious. For example, in R. v. Cey (1989) an amateur hockey player 
sustained injuries to his face after being hit during play. Cey was acquitted on the charge of assault causing bodily harm. Sports action happens quickly, and despite modern technologies that record it from various angles, it is not always possible to know if an act was part of a routine play or deliberately meant to injure.

Furthermore, actions in sport are often reactions making it difficult for a court to discern whether or not a player actually had the time to clearly think about the wrongfulness of their actions. Likewise, in the course of play, a player could get worked up or excited and be found to not be in the proper state of mind to decide right from wrong. Describing this, the judge presiding over Agar v. Canning (1966) stated, "The conduct of a player in the heat of the game is instinctive and unpremeditated and should not be judged by standards suited to polite social intercourse". Similarly, in Green (1971), the judge stated:

Where do you draw the line? It is very difficult in my opinion for a player who is playing with all of the force, vigour, and strength at his command, who is engaged in the rough and tumble of the game, very often in a rough situation in the corner of the rink, suddenly to stop and say, "I must not do that... maybe I am committing an assault.

From these cases, it could be argued that the fast action and emotions of the sport of ice-hockey negate questions of intent and culpability.

Furthermore, the deliberate harming of others is often within the objectives of certain sports. One of the most obvious examples is the sport of boxing, where as Jack Anderson (2007) suggests, the purpose is to assault one's opponent. Similarly, in sports like Canadian ice hockey where body contact is prevalent, it is an expected part of the game that players will try to lay one another out. The intent to cause some hurt to one another is clear; however, players are able to obfuscate the law if they can prove that they thought the act was consensual.

Beyond determining culpability is the issue of determining liability. Liability refers to who is at fault, and to what extent are they at fault (Hronek \& Spengler 2002). Thus far in this paper I have really only considered the criminal liability of the player who has committed a violent and injurious act. There are, however, other possible sanctions, such as civil liability or financial redress, as well as the liability of other individuals (Hronek \& Spengler 2002). This section will briefly explore who else might be liable in injurious sports injuries and what issues this might pose in sports litigation.

Non-players can and have been held liable for injuries in sport. For example, in two British cases (Smolden v. Whitworth 1997; Vowles v. Evans 2003) the referees of two separate rugby matches were both held civilly liable for the injuries that two players sustained as a result of undue care by the referee to keep control over the game (Caddell, 2004). In a Canadian case (Thomas v. Hamilton City Board of Education 1994), a high school football player sought damages from a Board of Education because of a broken neck he sustained during play that he believed resulted from improper coaching. Similarly, in Dunn v. University of Ottawa (1995), a football player successfully sought damages from the coach of the opposing team for failing to adequately control his players and coaching staff, which ultimately led to his injury. In this case, liability was transferred to the University of Ottawa, where the coach was employed. In a CFL case, Bell v. Edmonton Eskimos Football Club (1988), a player named James Anthony Bell sought damages against his football team for serious injuries that he believed resulted from the improper manufacturing of his helmet and the club's lack of investigation into the potential dangers of the product they supplied.

These cases reveal that there is a definite question of who is liable in cases involving sports violence, at least in terms of civil proceedings related to violence in sport. This raises the difficult issue, then, of who is at fault? The difficulties of this are similar to prosecuting any organization where it is difficult to pinpoint who is responsible (Linden 2000). Further to this, it is difficult to show the culpable intent of the various possible accused, as well as the degree to which the players consented to the activities of the accused. In the rugby case examples, it was decided that the players did not consent to undue care by the referee. Other examples, such as a Todd Bertuzzi's suggestion that his coach tapped him on the shoulder and told him to take care of Steve Moore before he violently injured him, might not be so clear (Moore v. Bertuzzi 2012).

\section{Conclusion}

In R. v. Maki (1970), one of the first criminal cases involving hockey violence, it was stated that "no sports league, no matter how well organized or self-policed it may be, should thereby render the players in that league immune from criminal prosecution." Wayne Maki was, however, never convicted for his violent act of on-ice assault that fractured Ted Green's skull causing him brain damage. In the decades that have followed, few cases of on-ice assault have appeared in Canadian courts; fewer still have resulted in convictions. For the most part, Canadian ice hockey has been permitted to govern itself in what could arguably be considered a state of 
exception from Canadian law. The rules, agreements, by-laws, voluntary associations, and disciplinary boards of Canadian hockey at different levels have been given an authority to create and enforce their owns laws as they see fit, apart from a few unique examples where Canadian legal officials have intervened. When legal officials do intervene, the cases are complex with many difficulties in discerning consent as outlined throughout this paper, leaving a question that has yet to be answered by the Canadian courts: what constitutes criminal assault in the context of Canadian ice hockey? Given the cultural and social significance of ice hockey in Canada this is a pertinent question that lawyers, judges, and legal scholars should work to address.

\section{References}

Agamben, G. (2005). State of exception. Chicago: University of Chicago Press.

Anderson, J. (2007). The legality of boxing: A punch drunk love? New York: Birkbeck Law Press.

Binder, R. (1975). The consent defense: Sports, violence, and the criminal law. American Criminal Law Review, $13,235-248$.

Caddell, R. (2004). The referee's liability for catastrophic sports injuries: A UK perspective. Marquette Sports Law Review, 15(1), 515-424.

Canadian Criminal Code. Retrieved from http:/laws.justice.gc.ca/en/

Corbett, R., Findlay, H., \& Lech, D. (2008). Legal issues in sport. Toronto: Edmond.

DiNicola, R., \& Mendeloff, S. (1983). Controlling violence in professional sports: Rule reform and the Federal Professional Sports Violence Commission. Duquesne Law Review, 21(4), 843-916.

Epstein, A. (2002). Sports law. Clifton Park, NY: Delmar Learning.

Hronek, B., \& Spengler, J. (2002). Legal liability in recreation and sports. Champaign, IL: Sagamore.

Linden, R. (2000). Criminology: A Canadian perspective. Scarborough, ON: Thomson Nelson.

Michigan Law Review Association. (1976). Consent in criminal law: Violence in sports. Michigan Law Review, 75(1), 148-179. Montgomery Publications Limited. http://dx.doi.org/10.2307/1287855

Voicu, A. (2005). Civil liability arising from breaches of sports regulations. The International Sports Law Journal, 1(2), 22-23.

White, D. (1986). Sports violence as criminal assault: Development of the doctrine by Canadian courts. Duke Law Journal, 6, 1030-1054. http://dx.doi.org/10.2307/1372629

\section{Cases}

Agar v. Canning (1966) 55 W.W.R. 384.

Bell v. Edmonton Eskimo Football Club, [1988] A. J. 1133.

Dunn v. University of Ottawa, [1995] O.J. 2856.

R. v. Bertuzzi, [2004] B.C.J. 2692.

R. v. Ciccarelli, [1989] O.J. 2388.

R. v. Henderson, [1976] 5 W.W.R. 119.

R. v. Maki, [1970] 16 D.L.R. (3d) 137.

R. v. McSorley, [2000] B.C.J. 1993.

R. v. Watson (1975), 26 C.C.C. (2d) 150.

Smolden v. Whitworth, [1997] E.L.R. 115.

Thomas (Next friend of) v. Hamilton Board of Education, [1994] O.J. 2444.

Vowles v. Evans, [2003] W.L.R. 1607.

\section{Copyrights}

Copyright for this article is retained by the author(s), with first publication rights granted to the journal.

This is an open-access article distributed under the terms and conditions of the Creative Commons Attribution license (http://creativecommons.org/licenses/by/3.0/). 